\title{
Should methyldibromo glutaronitrile continue to be used in the European baseline Series? A REIDAC national cross-sectional study
}

\author{
Pedro Mercader-García ${ }^{1}$ (c) | María Antonia Pastor-Nieto ${ }^{2}$ \\ Ricardo Gonzalez-Perez ${ }^{3}$ () | Susana Cordoba-Guijarro ${ }^{4}$ \\ Ana María Gimenez-Arnau ${ }^{5}$ \\ I Inmaculada Ruiz-Gonzalez ${ }^{6}$ () | \\ Verónica Mora-Fernández ${ }^{7}$ (1) | Javier Miquel ${ }^{8}$ |
}

Juan Francisco Silvestre-Salvador ${ }^{9}$ (1) | Francisco Javier Ortiz-Frutos ${ }^{10}$ () |

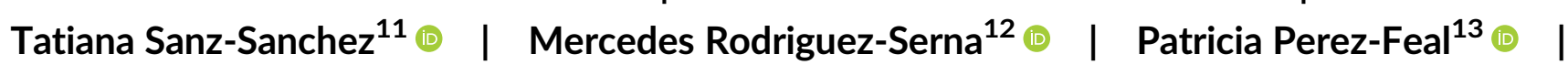

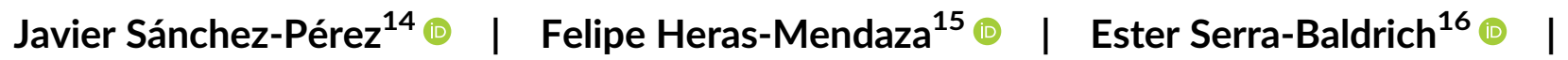

Violeta Zaragoza-Ninet ${ }^{17}$

Marcos Hervella-Garces ${ }^{18}$ (i) ।

María Elena Gatica-Ortega ${ }^{19}$ ( ) | Ignacio García-Doval ${ }^{20}$ (ㄱ) |

Miguel Ángel Descalzo ${ }^{20}$ ( ) | Leopoldo Borrego ${ }^{21}$ ( ) | the REIDAC group

\footnotetext{
${ }^{1}$ Deparment of Dermatology, Hospital General Universitario Jose Māa Morales Meseguer, Murcia, Spain

${ }^{2}$ Department of Dermatology, Hospital General Universitario de Guadalajara, Guadalajara, Spain

${ }^{3}$ Department of Dermatology, Hospital Universitario Araba, Vitoria, Spain

${ }^{4}$ Department of Dermatology, Hospital Universitario de Fuenlabrada, Fuenlabrada, Spain

${ }^{5}$ Department of Dermatology, Hospital del Mar. IMAS, Barcelona, Spain

${ }^{6}$ Department of Dermatology, Complejo Asistencial Universitario de León, Leon, Spain

${ }^{7}$ Department of Dermatology, Hospital General Universitari German Trias i Pujol, Barcelona, Spain

${ }^{8}$ Department of Dermatology, Hospital Arnau de Vilanova, Valencia, Spain

${ }^{9}$ Department of Dermatology, Hospital General Universitario, Alicante, Spain

${ }^{10}$ Department of Dermatology, Hospital General Universitario 12 de octubre, Madrid, Spain

${ }^{11}$ Department of Dermatology, Hospital General Universitario Infanta Sofia, Madrid, Spain

${ }^{12}$ Department of Dermatology, Hospital General Universitario La Fe, Valencia, Spain

${ }^{13}$ Department of Dermatology, Complejo Hospitalario Universitario Santiago de Compostela, Santiago de Compostela, Spain

${ }^{14}$ Department of Dermatology, Hospital Universitario La Princesa, Madrid, Spain

${ }^{15}$ Department of Dermatology, Hospital Fundación Jiménez Diaz, Madrid, Spain

${ }^{16}$ Department of Dermatology, Hospital de la Santa Creu i Sant Pau, Barcelona, Spain
}

The following collaborators of the REIDAC contributed data to this analysis: Juan Fco. Silvestre, Hospital General Universitario de Alicante, Alicante, (silvestre.jfr@gva.es); Ana Giménez Arnau, Hospital del Mar, Universitat Autónoma, Barcelona, (anamariagimenezarnau@gmail.com); Inmaculada Ruiz, Complejo Asistencial Universitario de León, León, (iruizgon@saludcastillayleon.es); Javier Sánchez-Pérez, Hospital Universitario la Princesa, Madrid, (jsanchezperez@aedv.es); Pedro Mercader-García, Hospital General Universitario Morales Meseguer, Murcia (pedromercader@hotmail.com); Virginia Fernández-Redondo, Complejo Hospitalario Universitario, Santiago de Compostela, (fernandezredondov@gmail.com), Verónica Mora Fernández Hospital Universitari Germans Trias i Pujol, Barcelona, (veroniamora@hotmail.com), Violeta Zaragoza, Consorcio Hospital General Universitario de Valencia (viozaragozaninet@gmail.com), Ricardo González(ricardo.gonzalezperez@osakidetza.eus), Javier Miquel, Hospital Arnau de Vilanova, Valencia, (fjmiquel0406@gmail.com), Susana Córdoba, Hospital Universiario de Fuenlabrada, Madrid, (susana.cordoba@salud.madrid.org), Tatiana Sanz-Sánchez, Hospital Universitario Infanta Sofia, Madrid, (tatiana@aedv.es), Ester Serra, Hospital de la Sant Pau i la Santa Creu, Barcelona, (eserrabaldrich@gmail.com), María Antonia Pastor-Nieto, Hospital General Universitario de Guadalajara, (mapastornieto@gmail.com), Javier Ortiz-Frutos, Hospital General Universitario 12 de Octubre, Madrid, (javierortiz@aedv.es), Felipe Heras-Mendaza, Fundación Jimenez Diaz, Madrid, (felipeheras@yahoo.com), Mercedes Rodríguez-Serna, Hospital General Universitario La Fé, Valencia, (merroser@gmail.com), Marcos Hervella-Garcés, Complejo Hospitalario de Navarra, Pamplona, (marcoshervellag@gmail.com), Jose Manuel Carrascosa Hospital Universitari Germans Trias i Pujol, Barcelona, (jmcarrascosac@hotmail.com), Patricia Perez-Feal, Complejo Hospitalario Universitario, Santiago de Compostela (patriciaperezfeal@gmail.com), Maria Elena Gatica-Ortega (mariaelenagatica@yahoo.com.ar), Leopoldo Borrego, Complejo Hospitalario Insular de las Palmas de Gran Canaria (leopoldo.borrego@ulpgc.es). 


\footnotetext{
${ }^{17}$ Department of Dermatology, Consorcio Hospital General Universitario de Valencia, Valencia, Spain

${ }^{18}$ Department of Dermatology, Complejo Hospitalario de Navarra, Pamplona, Spain

${ }^{19}$ Department of Dermatology, Complejo Hospitalario de Toledo, Toledo, Spain

${ }^{20}$ Research Unit, Fundación Piel Sana Academia Española de Dermatología y Venereología, Madrid, Spain

${ }^{21}$ Department of Dermatology, Complejo Hospitalario Universitario Insular Materno Infantil. Universidad de las Palmas de Gran Canaria, Las Palmas de Gran Canaria, Spain
}

Correspondence

Dr Pedro Mercader-García, Fundación Piel Sana AEDV, Ferraz 100, $1^{\circ}$ izda, Madrid 28008, Spain

Email: pedromercader@hotmail.com

\begin{abstract}
Background: Methyldibromo glutaronitrile (MDBGN) was one of the most frequent and relevant allergens found in patch testing at the beginning of this century. In 2008, this preservative was banned from cosmetics in Europe and ever since the prevalence of contact allergy to MDBGN has progressively decreased. Despite that gradual decline, MDBGN is still patch-tested in most baseline series. This study assessed the frequency of MDBGN sensitization, epidemiological characteristics of allergic patients, and the relevance of positive patch tests in a nationwide Spanish registry (REIDAC).
\end{abstract}

Patients and methods: We evaluated consecutively patch-tested patients in all participating centres. Using these data, we calculated the proportion of patients with positive patch tests to MDBGN from June 2018 to June 2020 and evaluated the relevance of the positive patch tests.

Results: One hundred and fourteen out of 5072 (2.24 \%) tested patients were sensitized to MDBGN. Clinical current relevance was confirmed in only one case.

Conclusion: Although the frequency of contact allergy to MDBGN remains high, no clinical significance was found in most of these patients (5072 tests needed to obtain one relevant positive result). The clinical usefulness of this allergen seems weak and its continued inclusion in the European baseline series is questionable.

\section{KEYWORDS}

allergic contact dermatitis, clinical relevance, cross-sectional study, methyldibromo glutaronitrile, patch tests

\section{1 | INTRODUCTION}

Methyldibromo glutaronitrile (MDBGN) (CAS no.35691-65-7, chemical name: 2-bromo-2-(bromomethyl)pentanedinitrile) was introduced in 1985 in Europe as a safe and cheap alternative to other preservatives. ${ }^{1}$ Soon after its introduction, several cases of allergic contact dermatitis to it were published..$^{2-4}$ During the $90 \mathrm{~s}$ and the early 2000s, this problem became epidemic. ${ }^{5}$ Because of these high rates of contact allergy with current relevance to MDBGN, it was included in the European baseline patch test series in $2005^{6}$ and, eventually, legislative measures were introduced in the European Union (EU) to reduce its health impact. Thus in $2005,{ }^{7}$ the European Commission banned MDBGN from being used in leave-on cosmetics and in $2008,{ }^{8}$ it was banned from rinse-off cosmetics. These policies led to a significant decrease in the prevalence of contact allergy to MDBGN. ${ }^{9,10}$ Accordingly, it was difficult to evaluate the relevance of most positive patch tests from then on. ${ }^{11,12}$ Some authors advocated maintaining MDBGN in the baseline series, based on possible non-regulated sources that could explain new cases of sensitization and dermatitis elicitation among young people. ${ }^{13}$ In this report we calculated the proportion of relevant positive tests in consecutive patients in several centres across Spain in order to evaluate whether the removal of MDBGN from European baseline series may be justified in our region.

The aims of our study were to (a) ascertain the current prevalence of contact allergy to MDBGN in a Spanish population and its clinical relevance among patients with positive patch tests; (b) detect statistically significant differences in qualitative variants using the MOAHLFA (male, occupational dermatitis, atopic dermatitis, hand dermatitis, leg dermatitis, face dermatitis, age $\geq 40$ years) index, between those patients allergic and non-allergic to MDBGN; and (c) check possible differences in the irritant properties between MDBGN in TRUEtest and petrolatum (pet.) 


\section{2 | PATIENTS AND METHODS}

We performed a cross-sectional study involving all patients included in the Spanish Allergic Contact Dermatitis Registry (REIDAC) and tested with the Spanish baseline series, ${ }^{14}$ including MDBGN. This registry was established in June 2018 and prospectively collects data from 20 tertiary centres with contact dermatitis units throughout Spain. It involves continuous online monitoring for data completeness and accuracy. MDBGN $0.5 \%$ pet. from Allergeaze (SmartPractice, Calgary, Canada) was patch tested in six centres, two centres used the same concentration from Chemotechnique Diagnostics (Vellinge, Sweden) and in 12 centres MDBGN $5 \mathrm{mcg} / \mathrm{cm}^{2}$ included in TRUE-test (MEKOS Laboratories A/S, Hillerød, Denmark) was used. Patch tests were performed according to the European Society of Contact Dermatitis patch test guidelines. ${ }^{15} \mathrm{~A}$ current relevance was considered as "certain" when exposure to a source of MDBGN was proven (eg, labelled in a suspicious product) and if a temporal relationship between the exposure and the occurrence of dermatitis was confirmed; "possible" relevance was considered whenever a repeated open application test (ROAT) or use test with a suspected (un)labelled culprit product (acquired outside the EU) was positive. A descriptive analysis was performed using the $\chi^{2}$ test and comparing data regarding the MOAHLFA index; for the study of the youngest participants we also added another variable, age $\geq 20$ years, in the descriptive analysis. $P$-values $<.05$ were considered significant. Logistic regression

TABLE 1 Results of patch testing MDBGN with TRUE-test and $0.5 \%$ pet

\begin{tabular}{|lccc|} 
& TRUE-test $\mathbf{n}(\%)$ & Pet. $\mathbf{n}(\%)$ & Total $\mathbf{n}(\%)$ \\
\hline Positive & $22(.74)$ & $92(4.38)$ & $114(2.24)$ \\
Doubtful & $2(.07)$ & $6(.29)$ & $8(.16)$ \\
\hline Irritant & 0 & $1(.05)$ & $1(.02)$ \\
\hline Negative & $2960(99.20)$ & $1998(95.28)$ & $4958(97.58)$ \\
\hline
\end{tabular}

Abbreviation: MDBGN, methyldibromo glutaronitrile. with odds ratios (ORs) and 95\% confidence intervals (Cls) were performed for the analysis of those variables with significant differences between those allergic and non-allergic to MDBGN. Irritant or doubtful readings were not included in the calculation of MOAHLFA. Data were recorded using the free online platform Openclinica, version 3.12 (https://www.openclinica.com/, Openclinica LLC, Massachusetts, RRID: SCR_019223) and analyzed with the program Stata software, version 16, (StataCorp LLC, Texas, RRID:SCR_012763).

\section{$3 \mid$ RESULTS}

From June 2018 to June 2020, 5081 patients were patch-tested, 2097 with MDBGN pet. and 2984 with TRUE-test. The results of patch tests with both preparations are shown in Table 1. One hundred and fourteen out of 5081 patients (2.24\%) were positive to MDBGN, but current relevance was found in case only one case involving a 73-year-old woman who used cosmetics bought outside the EU. Four additional positive tests were considered of past relevance, involving a 55-year-old woman with a past history of contact allergy to cosmetics; two retired women (72 and 69 years old) who had previously worked as office cleaners in contact with several cleaning detergents; and a 36-year-old man working as mechanic in contact with different oil products at work. Current exposure to products containing MDBGN could not be confirmed in any of the four patients; however, the clinical history evidenced past contact with this allergen in all cases.

The demographic characteristics of the patients regarding the MOAHLFA index are shown in Table 2. Most of our patients were non-atopic women with a non-occupational disease. The results of the bivariate analysis are shown in Table 2 . We only found significant differences regarding the variables age $>40$ and age $>20$, which remained when we performed logistic analysis of both variables (Table 3). Figure 1 shows an increased trend with age for being allergic to MDBGN for both TRUE-test and pet.

TAB LE 2 Demographic characteristics and results of logistic analysis of the patients regarding MOAHLFA index and age > 20 years

\begin{tabular}{|c|c|c|c|c|c|}
\hline Characteristic & $\begin{array}{l}\text { Negative test to } \\
\text { MDBGN, } n(\%)\end{array}$ & $\begin{array}{l}\text { Positive test to } \\
\text { MDBGN, } n(\%)\end{array}$ & $\begin{array}{l}\text { OR of positive } \\
\text { test }\end{array}$ & $95 \% \mathrm{Cl}$ & $P$-value \\
\hline Male & $1490(30.05)$ & 39 (34.21) & 1.21 & $.818-1.79$ & .33 \\
\hline Atopy & 790 (15.93) & $13(11.40)$ & .67 & $.37-1.20$ & .177 \\
\hline Hand & $1430(28.84)$ & $42(36.84)$ & 1.43 & $.97-2.11$ & .064 \\
\hline Age $>40$ & 3475 (70.09) & 94 (81.57) & 2.00 & $1.23-3.26$ & .004 \\
\hline Age $>20$ & 4607 (92.92) & $113(99.12)$ & 8.61 & $1.20-61.83$ & .032 \\
\hline
\end{tabular}

Note: $\mathrm{n}=$ number of patients, (\%) percentage with respect to the total of patients in each category.

Abbreviations: $\mathrm{Cl}$, confidence interval; MDBGN, methyldibromo glutaronitrile; MOAHLFA, male, occupational dermatitis, atopic dermatitis, hand dermatitis, leg dermatitis, face dermatitis, age $\geq 40$ years; OR odds ratio. 


\section{DISCUSSION}

In an epidemiological survey referencing the results of patch tests with the GEIDAC baseline series, performed in consecutive patients in 17 centres across Spain in 2012, Hervella-Garces et al ${ }^{14}$ found a prevalence of contact allergy to MDBGN of $2.09 \%$. In that research, current relevance of positive tests was $21 \%$. We observed a similar frequency of sensitization, but, unlike the previous study, current relevance could be ascertained in only one patient (1/114, $0.87 \%)$. Another Spanish study ${ }^{12}$ that analyzed data from 2004 to 2014 in eight centres, found contact allergy to MDBGN in 121 out of 8217 patients $(1.47 \%)$, with only four being of current relevance (4/121, 3.3\%).

Accurately defining relevance is difficult in any patch testing investigation. We contacted the office of the European Chemicals Agency (ECHA) in Spain and requested information regarding the current intended uses of MDBGN. ${ }^{16}$ Considered a type- 6 biocide, it can only be used as a preservative for water-based decorative paints applied by brush or roller indoors since 2015. Any manufacturer that intends to use it in Spain must ask for permission from the Spanish Ministry of Health. Since 2015 there have been no requests for this type of permission (P. Mercader, personal communication, july 25,2020$)$. Therefore, we only suspected current relevance regarding one patient who had been exposed to cosmetics

TAB LE 3 Adjusted odds ratio by hand and atopy of those variables with significant relevance in bivariate analysis

\begin{tabular}{llll} 
& OR of positive test & $95 \% \mathrm{Cl}$ & $P$-value \\
\hline Age $>40$ & 2.04 & $1.23-3.39$ & .006 \\
Age $>20$ & 7.74 & $1.07-56.06$ & .043 \\
\hline
\end{tabular}

Abbreviations: OR, odds ratio; $\mathrm{Cl}$, confidence interval. bought outside the EU. Although there are reports in Europe about the use of MDBGN in topical drugs ${ }^{17}$ or a detergent for leather, ${ }^{18}$ these cases must be considered the exception, rather than the rule, since a widespread non-compliance with the law seems unlikely. In terms of efficiency, our data show that when we patch test MDBGN as a component of the baseline series, it is necessary to perform 5072 tests to obtain one positive relevant result. ${ }^{12}$ Probably, most cases of contact allergy to MDBGN in our series represent historical sensitizations that developed years ago, when the use of this preservative was still widespread. The bivariate analysis of the MOAHLFA index support this hypothesis, as the only statistically significant difference in the ORs was found for the variable "age $>40$ ". If we consider the "age $>20$ ", then the differences in the ORs are even wider. Another explanation for these high levels of prevalence of MDBGN contact allergy is that patch tests with this substance are difficult to interpret, that is, false positives easily occur, ${ }^{19}$ mainly when higher concentrations are used. In patients patch-tested with MDBGN $0.5 \%$ pet., the dose per unit area is $200 \mathrm{mcg} / \mathrm{cm}^{2}$ (20 mg in a Finn chamber of $8 \mathrm{~mm}$ in diameter $)^{20}$ 40 times higher than in TRUE-test $\left(5 \mathrm{mcg} / \mathrm{cm}^{2}\right)$. This difference in concentration implies that a significant proportion of patients tested with MDBGN $0.5 \%$ pet. may represent irritant reactions, which may explain the differences in the proportion of positive tests that we found between both preparations (Table 1). Moreover, when we evaluated the proportion of positive tests for both preparations with regard to the age of the patients (Figure 1), we found that all the positive patients younger than 20 years of age had been patchtested with MDBGN $0.5 \%$ pet. Accordingly, we cannot rule out that some of the positive tests in this population actually represent irritant reactions.

The main limitation of our study is that the data came from centres located in a single country, but the regulatory issues are the same
FIGURE 1 Proportion of positive patch tests to methyldibromo glutaronitrile (MDBGN) in TRUE-test and pet. $0.5 \%$ according to age group

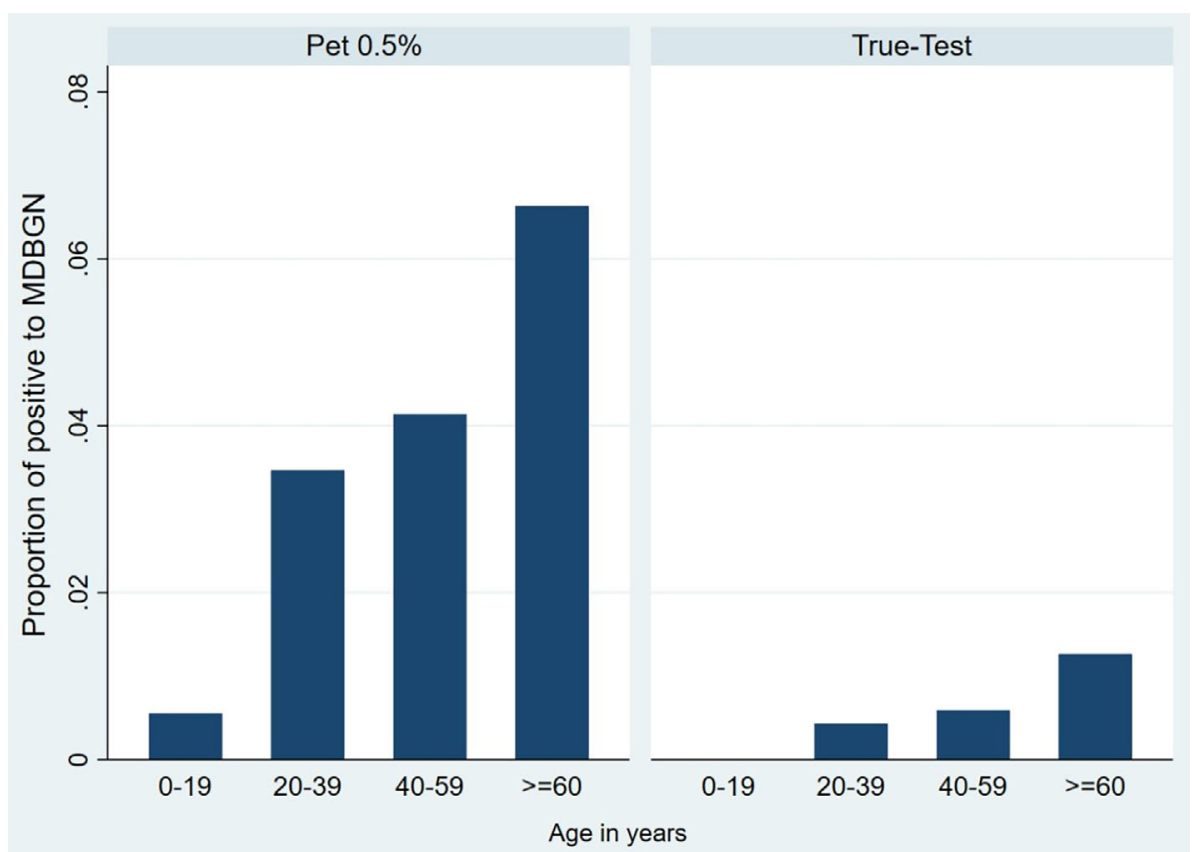


across the EU. In our opinion, the results may be extrapolated to any other country of the EU. However, further multinational studies are needed to confirm this hypothesis.

According to our results, MDBGN is today a highly inefficient contact allergen, mainly when higher doses are used and, in our opinion, should be removed from the European baseline series. However, we believe that MDBGN should remain in the specific series so that it can be patch tested if the clinical findings justify it.

\section{ACKNOWLEDGMENTS}

The following collaborators from the REIDAC, in addition to the authors, contributed data: Virginia Fernandez-Redondo, Jose Manuel Carrascosa, Mariana Lacentra, María del Mar Onteniente, Natalia Chaparro-Aguilera, Adria Plana-Pla, Claudia Cecilia OlmosNieva. The Spanish Registry of Contact Dermatitis (REIDAC) is promoted by the Fundación Piel Sana Academia Española de Dermatología y Venereología, which received an unrestricted grant support from Sanofi. Collaborating pharmaceutical companies were not involved in the design and conduct of the study, collection, management, analysis and interpretation of data, preparation, review, approval of the manuscript, or decision to submit the manuscript for publication.

\section{CONFLICT OF INTEREST}

The authors have no conflicts of interest to disclose.

\section{AUTHOR CONTRIBUTIONS}

Pedro Mercader: Conceptualization; formal analysis; funding acquisition; investigation; methodology; project administration; resources; validation; visualization; writing-original draft; writing-review \& editing. Maria Pastor-Nieto: Funding acquisition; investigation; project administration; resources; visualization; writing-original draft; writing-review \& editing. Ricardo González-Pérez: Funding acquisition; investigation; project administration; resources; writing-review \& editing. Susana Córdoba Guijarro: Funding acquisition; investigation; project administration; resources; writing-review \& editing. Ana Giménez-Arnau: Funding acquisition; investigation; project administration; resources; writing-review \& editing. Inmaculada RuizGonzález: Funding acquisition; investigation; project administration; resources; writing-review \& editing. Verónica Mora-Fernandez: Investigation; project administration; writing-review \& editing. Javier Miquel Miquel: Funding acquisition; investigation; project administration; resources. juan francisco silvestre: Funding acquisition; investigation; project administration; resources; writing-review \& editing. Javier Ortiz de Frutos: Funding acquisition; investigation; project administration; resources; writing-review \& editing. Tatiana SanzSanchez: Funding acquisition; investigation; project administration; resources; writing-review \& editing. Mercedes Rodriguez-Serna: Funding acquisition; investigation; project administration; resources; writing-review \& editing. Patricia Pérez-Feal: Investigation; writingreview \& editing. Javier Sanchez-Perez: Funding acquisition; investigation; project administration; resources; writing-review \& editing. Felipe Heras-Mendaza: Funding acquisition; investigation; project administration; resources; writing-review \& editing. Esther Serra Baldrich: Funding acquisition; investigation; project administration; resources. Violeta Zaragoza Ninet: Funding acquisition; investigation; project administration; resources. Marcos Hervella-Garcés: Funding acquisition; investigation; project administration; resources. MariaElena Gatica-Ortega: Funding acquisition; investigation; project administration; resources. Ignacio García-Doval: Formal analysis; methodology; resources; supervision; validation; writing-original draft; writing-review \& editing. Miguel Angel Descalzo: Data curation; formal analysis; methodology; resources; software; validation; visualization; writing-original draft; writing-review \& editing. Leopoldo Borrego: Conceptualization; funding acquisition; investigation; methodology; project administration; resources; supervision; validation; writing-review \& editing.

\section{DATA AVAILABILITY STATEMENT}

Data available on request from the authors.

\section{ORCID}

Pedro Mercader-García (D) https://orcid.org/0000-0002-8309-9725 María Antonia Pastor-Nieto (D) https://orcid.org/0000-0001-83825419

Ricardo Gonzalez-Perez (D) https://orcid.org/0000-0001-5238-215X Susana Cordoba-Guijarro (D) https://orcid.org/0000-0002-1809-4821 Ana María Gimenez-Arnau (D) https://orcid.org/0000-0001-54347753

Inmaculada Ruiz-Gonzalez (D) https://orcid.org/0000-0002-5101-466X Verónica Mora-Fernández (D) https://orcid.org/0000-0003-0016-9781 Juan Francisco Silvestre-Salvador (D) https://orcid.org/0000-00028532-6338

Francisco Javier Ortiz-Frutos (D) https://orcid.org/0000-0002-06350971

Tatiana Sanz-Sanchez (D) https://orcid.org/0000-0002-5796-7680 Mercedes Rodriguez-Serna (D) https://orcid.org/0000-0002-2690-3668 Patricia Perez-Feal (D) https://orcid.org/0000-0002-3906-5026 Javier Sánchez-Pérez (D) https://orcid.org/0000-0003-1240-1015 Felipe Heras-Mendaza (D) https://orcid.org/0000-0002-5016-173X Ester Serra-Baldrich (D) https://orcid.org/0000-0001-7603-0300 Marcos Hervella-Garces (D) https://orcid.org/0000-0001-5238-9562 María Elena Gatica-Ortega (ID https://orcid.org/0000-0002-82035834

Ignacio García-Doval (D) https://orcid.org/0000-0002-6881-5260 Miguel Ángel Descalzo (D) https://orcid.org/0000-0002-2262-7547 Leopoldo Borrego (D) https://orcid.org/0000-0002-0199-2756

\section{REFERENCES}

1. Aakhus $A E$, Warshaw EM. Allergy to methyldibromoglutaronitrile/ phenoxyethanol (Euxyl K 400): regulatory issues, epidemiology, clinical characteristics, and management. Dermatitis. 2011;22(3):127-140. https://doi.org/10.2310/6620.2011.10081

2. Senff H, Exner M, Görtz J, Goos M. Allergic contact dermatitis from Euxyl K 400. Contact Dermatitis. 1989;20(5):381-382. https://doi. org/10.1111/j.1600-0536.1989.tb03180.x 
3. Pigatto PD, Bigardi A, Legori A, Altomare GF, Carminati G. Allergic contact dermatitis from Tektamer 38 (dibromocyanobutane). Contact Dermatitis. 1991;25(2):138-139. https://doi.org/10.1111/j.16000536.1991.tb01815.x

4. Ross JS, Crokin E, White IR, Rycroft RJG. Contact dermatitis from Euxyl K 400 in cucumber eye gel. Contact Dermatitis. 1992;26(1):6060. https://doi.org/10.1111/j.1600-0536.1992.tb00878.x

5. Wilkinson JD, Shaw S, Andersen KE, et al. Monitoring levels of preservative sensitivity in Europe: a 10-year overview (1991-2000). Contact Dermatitis. 2002;46(4):207-210. https://doi.org/10.1034/j.16000536.2002.460404.x

6. Bruze M, Goossens A, Gruvberger B. Recommendation to include methyldibromo glutaronitrile in the European standard patch test series. Contact Dermatitis. 2005;52(1):24-28. https://doi.org/10. 1111/j.0105-1873.2005.00482.x

7. EUR-Lex - 32003L0083 - EN - EUR-Lex. https://eur-lex.europa.eu/ legal-content/EN/TXT/?uri=uriserv\%3AOJ.L_.2003.238.01.0023.01. ENG\&toc $=$ OJ\%3AL\%3A2003\%3A238\%3ATOC. Accessed November 15, 2020.

8. EUR-Lex - 32007L0017 - EN - EUR-Lex. https://eur-lex.europa.eu/ eli/dir/2007/17/oj. Accessed November 15, 2020.

9. Johansen JD, Veien N, Laurberg G, et al. Decreasing trends in methyldibromo glutaronitrile contact allergy - following regulatory intervention. Contact Dermatitis. 2008;59(1):48-51. https://doi.org/10. 1111/j.1600-0536.2008.01364.x

10. Schnuch A, Lessmann H, Geier J, Uter W. Contact allergy to preservatives. Analysis of IVDK data 1996-2009. Br J Dermatol. 2011;164(6): 1316-1325. https://doi.org/10.1111/j.1365-2133.2011.10253.x

11. Schwensen JF, White IR, Thyssen JP, Menné T, Johansen JD. Failures in risk assessment and risk management for cosmetic preservatives in Europe and the impact on public health. Contact Dermatitis. 2015;73 (3):133-141. https://doi.org/10.1111/cod.12446

12. García-Gavín J, Mercader P, Descalzo MA, et al. Efficiency in patch testing: the number needed to test to get one relevant result as a new approach in the evaluation of baseline series. $\mathrm{Br} J$ Dermatol. 2020;183(2):391-393. https://doi.org/10.1111/bjd.18975

13. Giménez-Arnau AM, Deza G, Bauer A, et al. Contact allergy to preservatives: ESSCA* results with the baseline series, 2009-2012. J Eur
Acad Dermatology Venereol. 2017;31(4):664-671. https://doi.org/10. 1111/jdv.14063

14. Hervella-Garcés M, García-Gavín J, Silvestre-Salvador JF. Actualización de la serie estándar española de pruebas alérgicas de contacto por el Grupo Español de Investigación en Dermatitis de Contacto y Alergia Cutánea (GEIDAC) para 2016. Actas Dermosifiliogr. 2016;107(7):559-566. https://doi.org/10.1016/j.ad.2016.04.009

15. Johansen JD, Aalto-Korte K, Agner T, et al. European Society of Contact Dermatitis guideline for diagnostic patch testing - recommendations on best practice. Contact Dermatitis. 2015;73(4):195-221. https://doi.org/10.1111/cod.12432

16. Biocidal Products Committee (BPC). https://echa.europa.eu/ documents/10162/ee68ecaf-7d48-4bb5-9842-3dfbb5d3e7a7. Accessed November 29, 2020.

17. Amaro C, Cravo M, Fernandes C, Santos R, Gonçalo M. Undisclosed methyldibromo glutaronitrile causing allergic contact dermatitis in a NSAID cream. Contact Dermatitis. 2012;67(3):173-174. https://doi. org/10.1111/j.1600-0536.2012.02091.x

18. Kamstrup MR, Bandier J, Johansen JD, Thyssen JP. Contact allergy to methyldibromo glutaronitrile is still of clinical relevance. Contact Dermatitis. 2017;77(4):250-251. https://doi.org/10.1111/cod.12768

19. Schnuch A, Schubert S, Geier J. Clinicians vs. epidemiologists: patch testing with methyldibromo glutaronitrile as a controversial issue. J Eur Acad Dermatology Venereol. 2019;33(6):e242-e244. https://doi. org/10.1111/jdv.15505

20. Wilkinson $M$, Gonçalo $M$, Aerts $O$, et al. The European baseline series and recommended additions: 2019. Contact Dermatitis. 2019;80(1):14. https://doi.org/10.1111/cod.13155

How to cite this article: Mercader-García P, Pastor-Nieto MA, Gonzalez-Perez R, et al. Should methyldibromo glutaronitrile continue to be used in the European baseline Series? A REIDAC national cross-sectional study. Contact Dermatitis. 2021;85:572-577. https://doi.org/10.1111/cod.13837 